\title{
USER EXPERIENCE AND DIGITALLY TRANSFORMED/CONVERTED EMOTIONS
}

\author{
Mohammad Rafat Odeh ${ }^{1,}$ Dr. Badie Sartawi ${ }^{2}$, Dr. Jad Najjar ${ }^{3}$ \\ ${ }^{1}$ Information \&Technology Center, Al-Quds Open University, Palestine \\ ${ }^{2}$ Faculty of Science \&Technology, Department of Computer Science, Al- \\ Quds University, Palestine \\ ${ }^{3}$ Faculty of Science \&Technology, Department of Computer Science, Al-Quds \\ University, Palestine
}

\begin{abstract}
In human natural interaction (human-human interaction), humans use speech beside the non-verbal cues like facial expressions movements and gesture movements to express themselves. However, in (humancomputer interactions), computer will use the non-verbal cues of human beings to determine the user experience and usability of any software or application on the computer. We introduce a new model called Measuring User Experience using Digitally Transformed/Converted Emotions (MUDE) which measures two metrics of user experience(satisfaction and errors), and compares them with SUS questionnaire results by conducting an experiment for measuring the usability and user's experience.
\end{abstract}

\section{KEYWORDS}

Usability, User Experience, Emotions, Facial Expressions, Gestures, MUDE Model.

\section{INTRODUCTION}

There are many evaluation methods and techniques used for testing user experience, in order to produce an effective and efficient software. One of the modern techniques is using facial expressions and gestures to expect the user interaction and perception of the developed software, this technique depends on user face and gestures. Taking into consideration, those human facial expressions and body gestures are very significant means of communication between people as they provide important information and help deliver peoples communicative aim. Humans learn to recognize facial expressions long before they learn to communicate verbally (Harty, 2011). Faces and gestures not only provide us with the primary source of information about the people that we are communicating with like there sex or gender, but also provide us extra communicative functions like how they manage the conversation and how they express themselves towards what is being said.

Faces and gestures are also excellent ways in a conversation for showing confirmation or surprise without saying any word. Therefore, facial expressions and gestures are the most effective way for communicating emotions of people (Harty, 2011).

\section{METHODOLOGY}

Our paper focuses on investigating a new approach for determining usability and user experience indicators for any application used for any purpose. We will capture the expressed emotions either positive or negative (digitally transformed/converted emotions) through face or hand over 
International Journal of Managing Information Technology (IJMIT) Vol.10, No.2, May 2018

face gestures while using application software, these emotions will be used to measure two parameters of usability and user experience satisfaction and errors.

The proposed methodology is a new approach, it maps the two usability and user experience parameter into emotions. Each one of these emotions has its specific facial expressions and specific hand over face gestures. In this way, we leave the traditional tools of usability engineering and the user is the source of information.

An empirical experiment was carried out to show how the user expresses his or her emotions in critical incidents. This study use in experiment an interactive camera manufactured by Intel that reads emotions instantly(https://software.intel.com/en-us/articles/developing-applications-usingintel-perceptual-computing-technology,29/7/2017).

\section{WHY BODY LANGUAGE}

The human behavioural cues consist of human emotional cues that contain visual cues including nonverbal cues that the body language is one of its types. In addition, that body language comprises of facial expressions, hand gestures and other cues.

Allan Pease in his book (the definitive book of body language) defined the body language as an outward reflection of a person's emotional condition. (Pease and Pease, 2004) confirmed that each gesture or movement can indicate a person emotional state or feeling at a specific time. Body language is "a type of nonverbal communication that plays a central role in how humans communicate and empathizes with each other. The ability to read nonverbal cues is essential for understanding, analyzing, and predicting the actions and intentions of others" (Mahmoud and Robinson, 2011).

Humans from different cultures, and in various situations can communicate, and interacted with a certain level of accuracy when they observe both the face and the body (Mahmoud and Robinson, 2011).

\section{EMOTIONS AND DIGITALLY TRANSFORMED/CONVERTED EMOTIONS}

Emotion is an essential ingredient for human that is complex and hard to find a consensus on its definition. The emotion like joy, anger, disgust and plethora of other emotion add an active motivation and richness for human experience. (Brave and Nass, 2003)

Paul and Anne Kleinginna research study (a categorized list of emotion definitions, with suggestions for consensual definition) that contains a different collection of emotion definitions, stated that emotion has two important aspects:

(a) emotion is a reaction to events related to the needs, goals, or concerns of human (b) emotion includes physiological, affective, behavioral, and cognitive component (Brave and Nass, 2003). These two general aspects are extracted from many different definitions that Kleinginnas have mentioned in their research study.

Many emotions appear on human face and body; these emotions are translated through body language, facial expressions and gestures. We differentiate these emotions and call them digitally transformed/converted emotions. Emotions resulting from the interaction of human with PC, pocket, smart phone, or any computer device is digitally transformed/converted emotions. These digitally transformed/converted emotions carry the same aspects and characteristics of regular 
International Journal of Managing Information Technology (IJMIT) Vol.10, No.2, May 2018 emotions, and we can measure them using the same tools in regular emotions that result from human-human interaction.

\section{INFERRING EMOTIONS}

Human can express his feelings and emotions using verbal and nonverbal cues. Nonverbal cues have their own channels to transfer feelings and emotions such as text, audio, physiology and visual. One of the visual communications or transfer channels is body language that includes hand gestures, body pastures, and facial expressions etc.

Facial expressions are created as result of contract of face muscles, the operation of face muscular relaxation and contraction deform the facial expression system. Each facial deformation have its feeling or emotion meaning. Recognizing facial expression depends on many factors like the classification of facial motion and facial feature deformation to abstract classes based on visual information (Fasel and Luettin, 2002). Facial expressions are generated from different factors such as verbal and nonverbal communications, mental state and physiology activity.

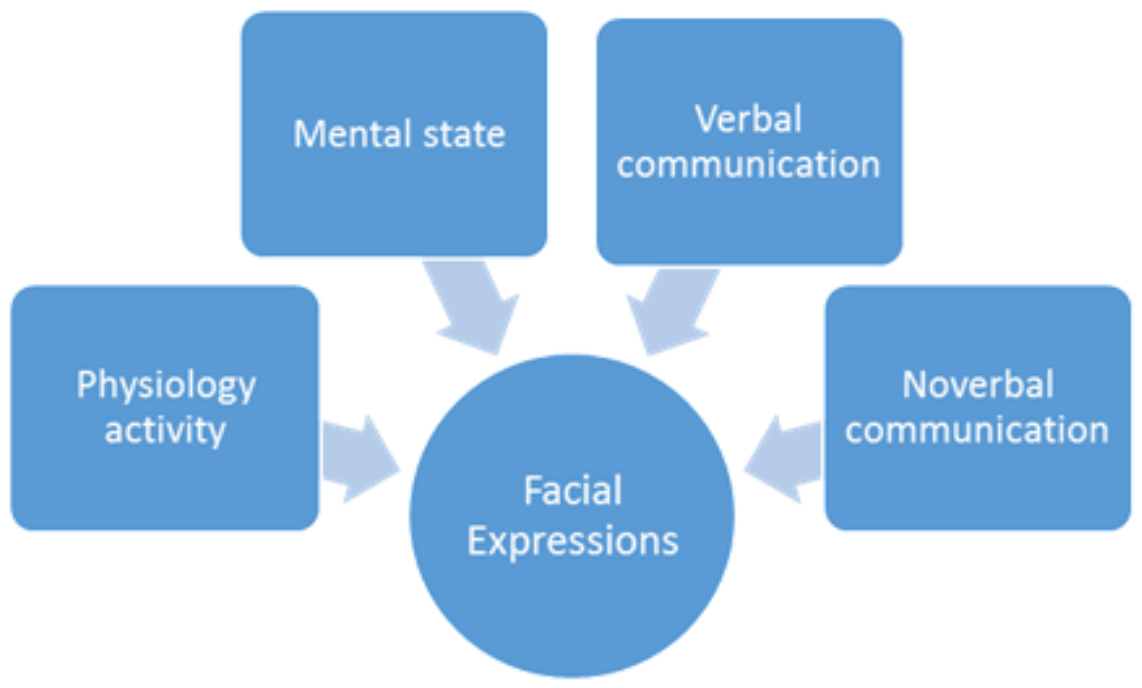

Figure1. Sources of facial expression (Adopted from (Fasel and Luettin, 2002))

Besides that, face transmits messages about emotion, mood, age etc. Therefore, the face is also a multi message system (Ekman and Friesen, 1975).

\section{PSYCHOLOGICAL APPROACHES OF FACIAL EXPRESSIONS ANALYSIS}

\subsection{Judgment based approaches or "message judgment approaches"}

The objective of this approach is to indicate the message behind the facial expression. The facial expression or mental status have its predefined class of emotions. Coders' group consensus on emotions inferred from facial expression or mental status by computing the average of the responses of the users, this consensus possessed the absolute truth (Fasel and Luettin, 2002). A problem in judgment-based approach is that it may be affected by context of observation behavior of human face (Bettadapura, 2012). This approach is correspond to Facial effect (emotions) approach which used by researchers in automatic analysis of facial expressions. The Ekman's six 
International Journal of Managing Information Technology (IJMIT) Vol.10, No.2, May 2018

emotions approach, Pultchik's approach ,Russell's approach and Monitoring hand over face gestures are examples of Judgment based approaches (facial effect ).

\section{2-Sign based approaches or "vehicle based approaches"}

The basic idea behind vehicle-based approach is to characterize the facial muscles movements and temporary wrinkles that face create into visual classes, each movement is determined by its location and intensity. A complete system contains all possible forms of face (Fasel and Luettin, 2002). This approach is correspond to facial muscles action (action unit) approach which used by researchers in automatic analysis of facial expressions the Facial Action Coding System (FACS), Facial Animation Parameters (FAPs) MPEG-4 standard

\section{USER EXPERIENCE AND USABILITY}

Some experts defined the two terms as metaphor to clear the contrast between the two terms. They compared them to science (usability) vs. arts (user experience) and freeway (usability) vs. a twisting mountain road (user experience). This metaphorical representation is trying to describe usability as "something that is usable as functional, simple and requires less mental effort to use. Thus, a freeway is usable since it has no oncoming traffic, enables you to get from point A to point $\mathrm{B}$ in a fast manner and has consistent signage, hence requiring little learnability". In contrast, user experience is "a freeway is highly usable but it is boring when assessed. It is something that focuses on user experience depicted as highly emotional. Thus, a twisting mountain road is less usable but, because of its scenery, the smell of nature and the excitement of the climb, it conveys a pleasant user experience".(https://usabilitygeek.com/the-differencebetween-usability-and-user-experience/)

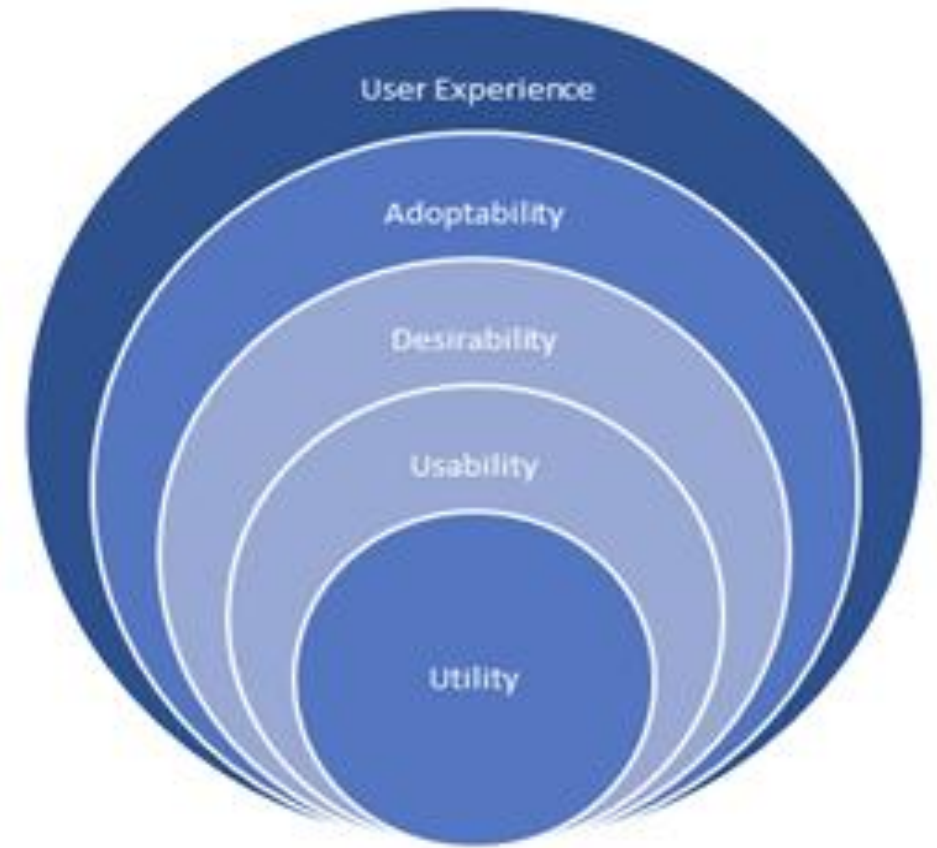

Figure 2. The relationship between usability and user experience (Adopted from (Moville, 2004)) 
International Journal of Managing Information Technology (IJMIT) Vol.10, No.2, May 2018

\section{MEASURING USER EXPERIENCE USING DIGITALLY TRANSFORMED/ CONVERTED EMOTIONS (MUDE MODEL)}

\subsection{MUDE Model Components}

We can summarized the components of MUDE as follow

\section{1- User Experience Parameters "Usability Parameters “}

Usability have its parameters Learnability, satisfaction, errors, efficiency and memorability. On the other hand user experience have its specific parameters utility, usability, desirability and adoptability .So, usability is a metrics of user experience and if we measure usability we can measure user experience .In other words, measuring Learnability, satisfaction, errors, efficiency and memorability give us user experience.

2- The Emotions that Related to User Experience Parameters

Depending on Pultchik's wheel we can map each user experience parameter with its expected or related emotions based on its meaning as follow:

Table 1.MUDE Model Mapping of User experience parameters

\begin{tabular}{|c|c|c|}
\hline $\begin{array}{c}\text { User Experience } \\
\text { Parameters }\end{array}$ & Meaning of It Parameter & Related Primary Emotions \\
\hline Satisfaction & How pleasant to use software & Joy \\
\hline Learnability & $\begin{array}{l}\text { How easy is it for users to accomplish } \\
\text { basic tasks the first time they encounter } \\
\text { the design? }\end{array}$ & Joy \\
\hline Efficiency & $\begin{array}{l}\text { Once users have learned the design, how } \\
\text { quickly can they perform tasks }\end{array}$ & Joy \\
\hline Memorability & $\begin{array}{l}\text { When users return to the design after a } \\
\text { period of not using it, how easily can } \\
\text { they reestablish proficiency? }\end{array}$ & Joy \\
\hline Errors & Errors occurrence & $\begin{array}{l}\text { Anger, ,Surprise, contempt } \\
\text {,disgust, fear ,sadness }\end{array}$ \\
\hline
\end{tabular}

3 -Measuring Systems that Inferring Emotions from Facial Expressions and Hand over Face Gestures. Integrating the three previous components together, we can have a MUDE model. The following table explains the mapping between the metrics, expected emotions, action unit, FAPs and Pease \& Pease. We take the satisfaction as example for mapping between components. 
International Journal of Managing Information Technology (IJMIT) Vol.10, No.2, May 2018

Table 2. MUDE Model Mapping of User experience parameters $\rightarrow$ relative emotion $\rightarrow$ FACS $\rightarrow$ FAPs $\rightarrow$ Pease \& Pease

\begin{tabular}{|c|c|c|c|c|c|}
\hline \multirow{2}{*}{$\begin{array}{c}\text { User } \\
\text { Experience } \\
\text { (usability ) } \\
\text { Parameters }\end{array}$} & \multirow{2}{*}{$\begin{array}{l}\text { Emotions } \\
\text { (That } \\
\text { related to } \\
\text { UX) }\end{array}$} & \multicolumn{3}{|c|}{ Inferring Methods } & \multirow[t]{2}{*}{ Logs } \\
\hline & & FACS & FAPs & $\begin{array}{c}\text { Pease \& } \\
\text { Pease }\end{array}$ & \\
\hline $\begin{array}{c}\text { Satisfaction } \\
\text { (How pleasant } \\
\text { is it to use the } \\
\text { software) }\end{array}$ & Joy & $6+12$ & $\begin{array}{l}\text { open jaw (F3), lower t } \\
\text { midlip (F4), raise b midlip } \\
\text { (F5), stretch } 1 \text { corner lip } \\
\text { (F6), stretch r corner lip } \\
\text { (F7), raise } 1 \text { corner lip } \\
\text { (F12), raise r corner lip } \\
\text { (F13), close } \mathrm{t} \text { l eyelid } \\
\text { (F19), close t r eyelid } \\
\text { (F20), close b l eyelid } \\
\text { (F21), close b r eyelid } \\
\text { (F22), raise } 1 \text { m eyebrow } \\
\text { (F33),raise r m eyebrow } \\
\text { (F34), lift } 1 \text { cheek (F41), } \\
\text { lift r cheek (F42), stretch } 1 \\
\text { corner lip o (F53),stretch r } \\
\text { corner lip o (F54) }\end{array}$ & PP3 & $\begin{array}{l}\text { Review the } \\
\text { recording of log } \\
\text { file and see if } \\
\text { user have been } \\
\text { learn the } \\
\text { methods of } \\
\text { filling forms in } \\
\text { addition we will } \\
\text { consider the } \\
\text { post - } \\
\text { questionnaire }\end{array}$ \\
\hline
\end{tabular}

\section{SUS QUESTIONNAIRE MEETS INTEL INTERACTIVE GESTURES CAMERA DESCRIPTION OF THE EXPERIMENT}

The hypothesis of experiment is that the attitudes of users emotions captured by Intel interactive gesture camera that use FAPs model about usability, are consistent with the attitudes of users in a paper based on SUS questionnaire about usability. In addition, we aim to complete the analysis process by using SPSS 19 (Orfanou, Tselios, and Katsanos,2015).

\subsection{Participants}

The number of participants is 70 participants (44 males and 26 females) with different ages ranging from 19 to 42 . The academic background of participants:56 B.A (16 Media and Television, 7 Computer Science, 2 IT, 1 MIS, 2 Mathematics, 1 Physics and 1 political science), and 14 M.A(6 Computer Science, 1 Public Health and 7 MBA/ Entrepreneurial ).

\subsection{Experiment Environment}

The experiment is done in unconstraint environment. 
International Journal of Managing Information Technology (IJMIT) Vol.10, No.2, May 2018

\subsection{Procedure (Scenario)}

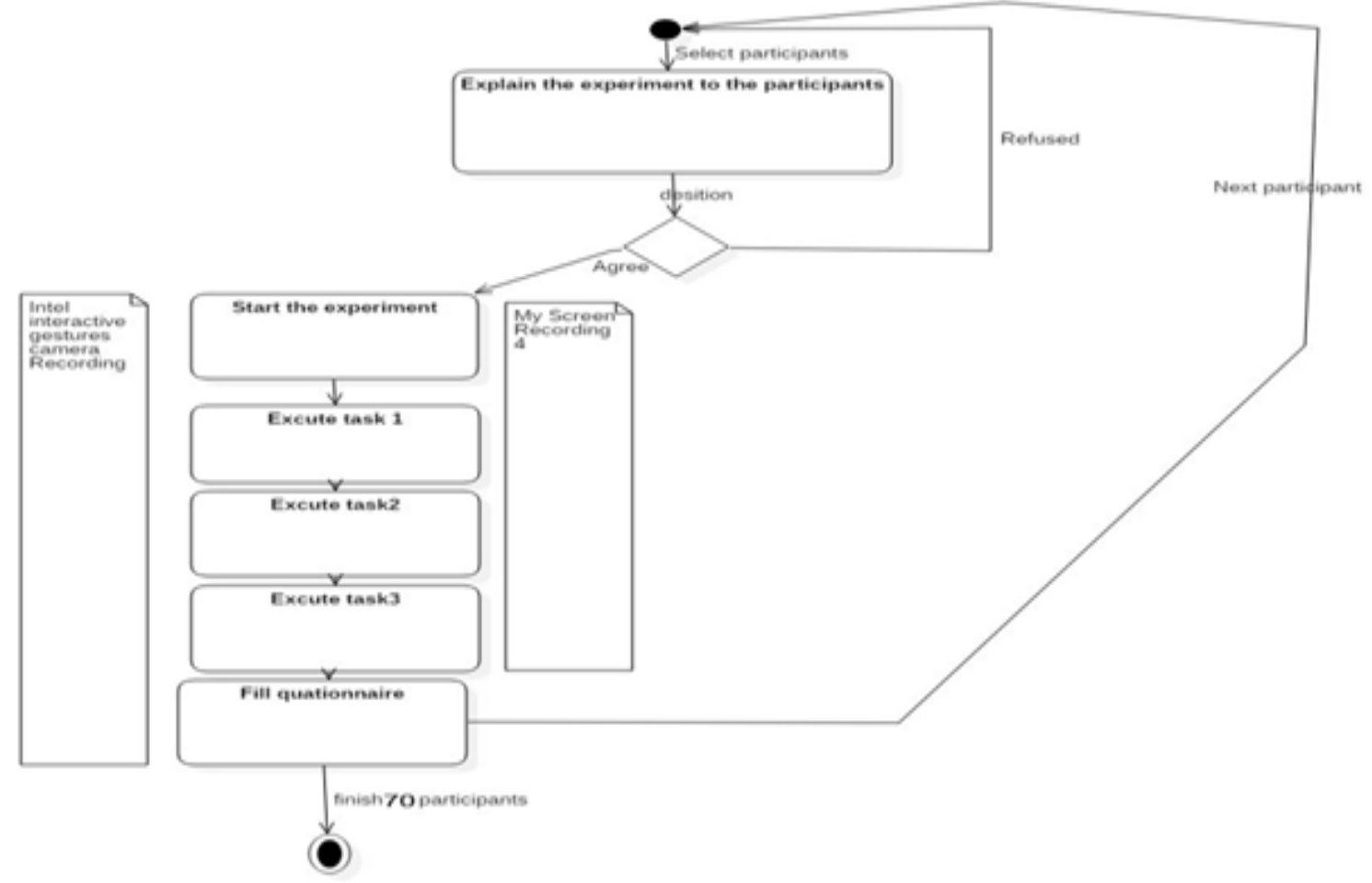

Figure 2: Sketch Explain the Procedure of Experiment

\subsection{Apparatus}

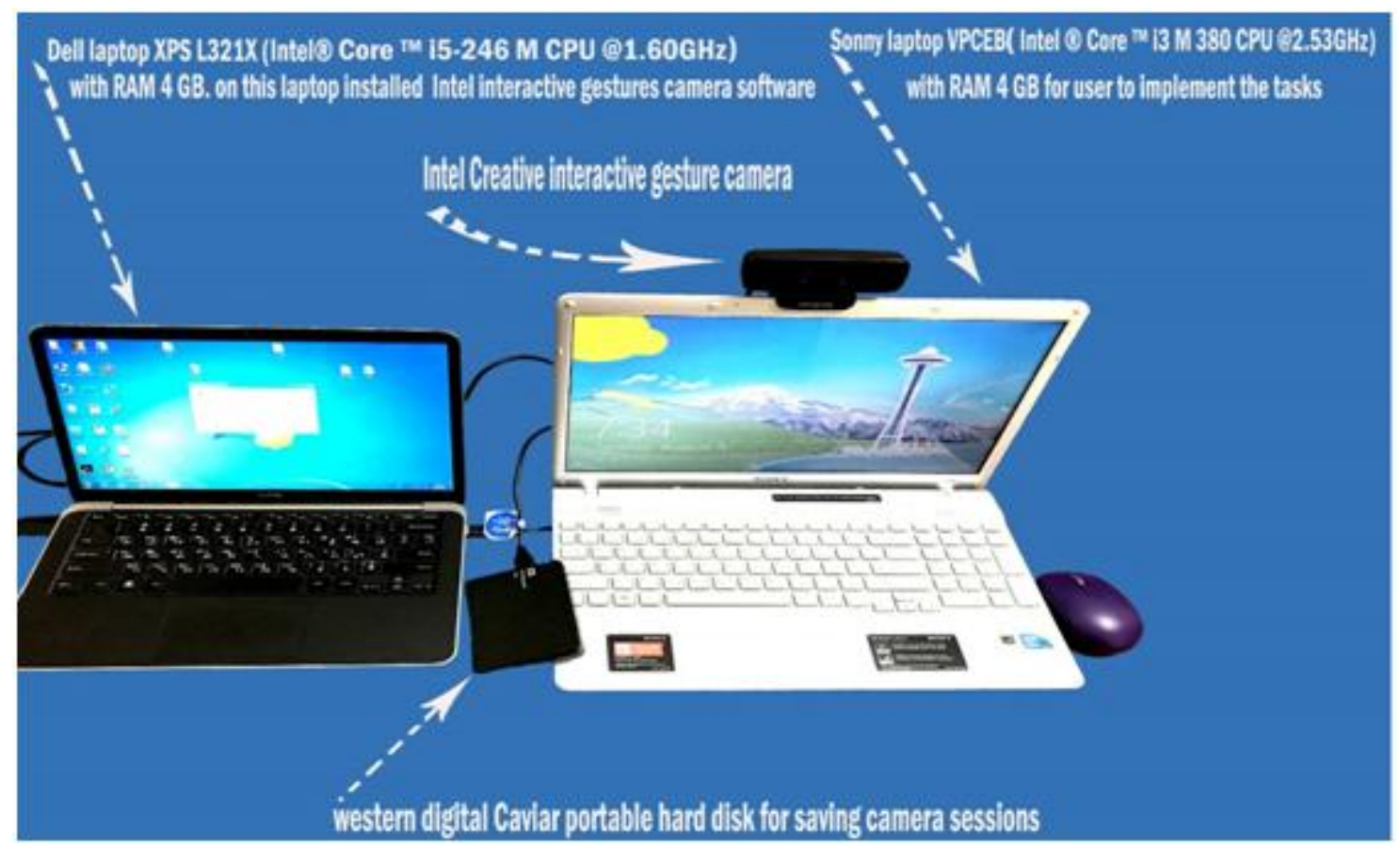

Figure 3. Experiment Layout 


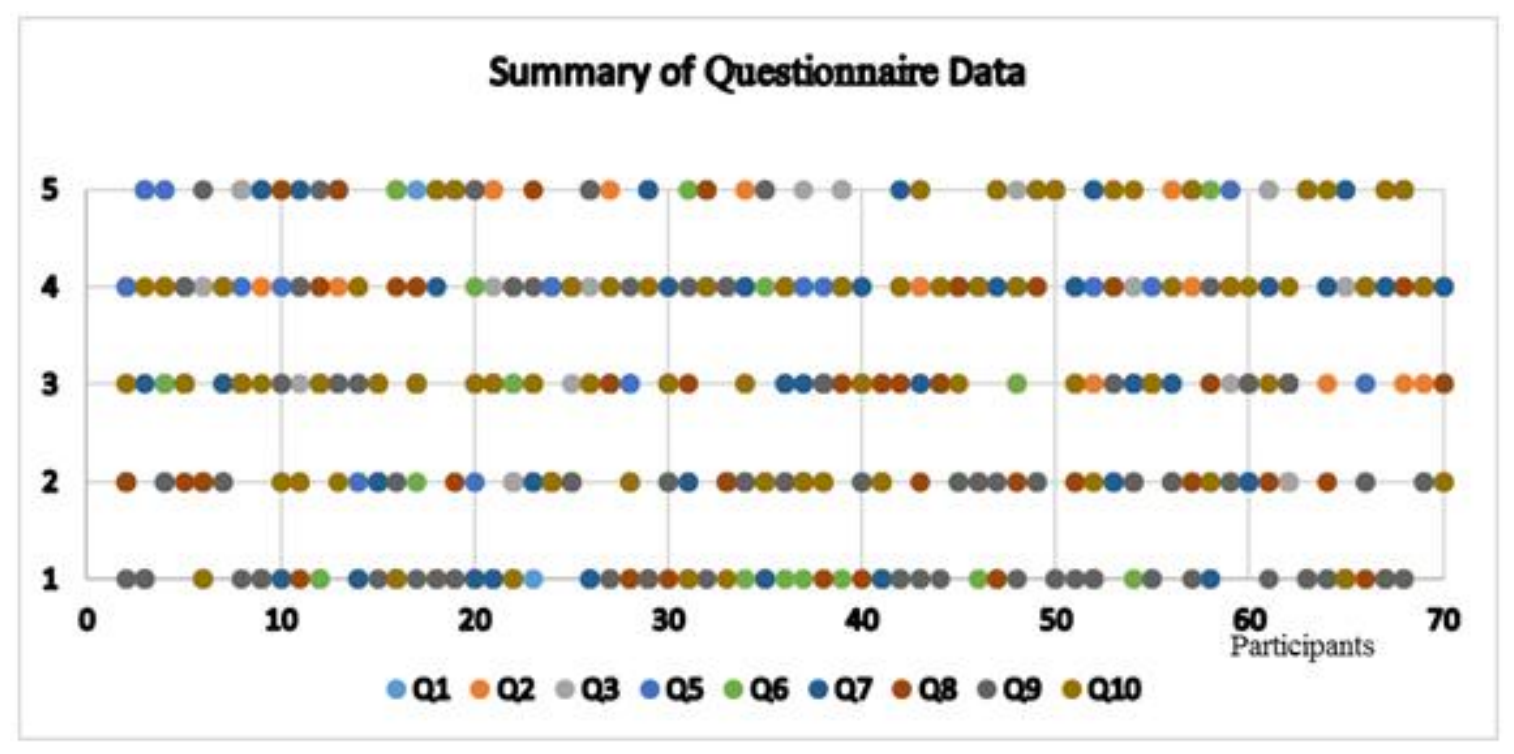

Figure 4. Summary of Questionnaire Data

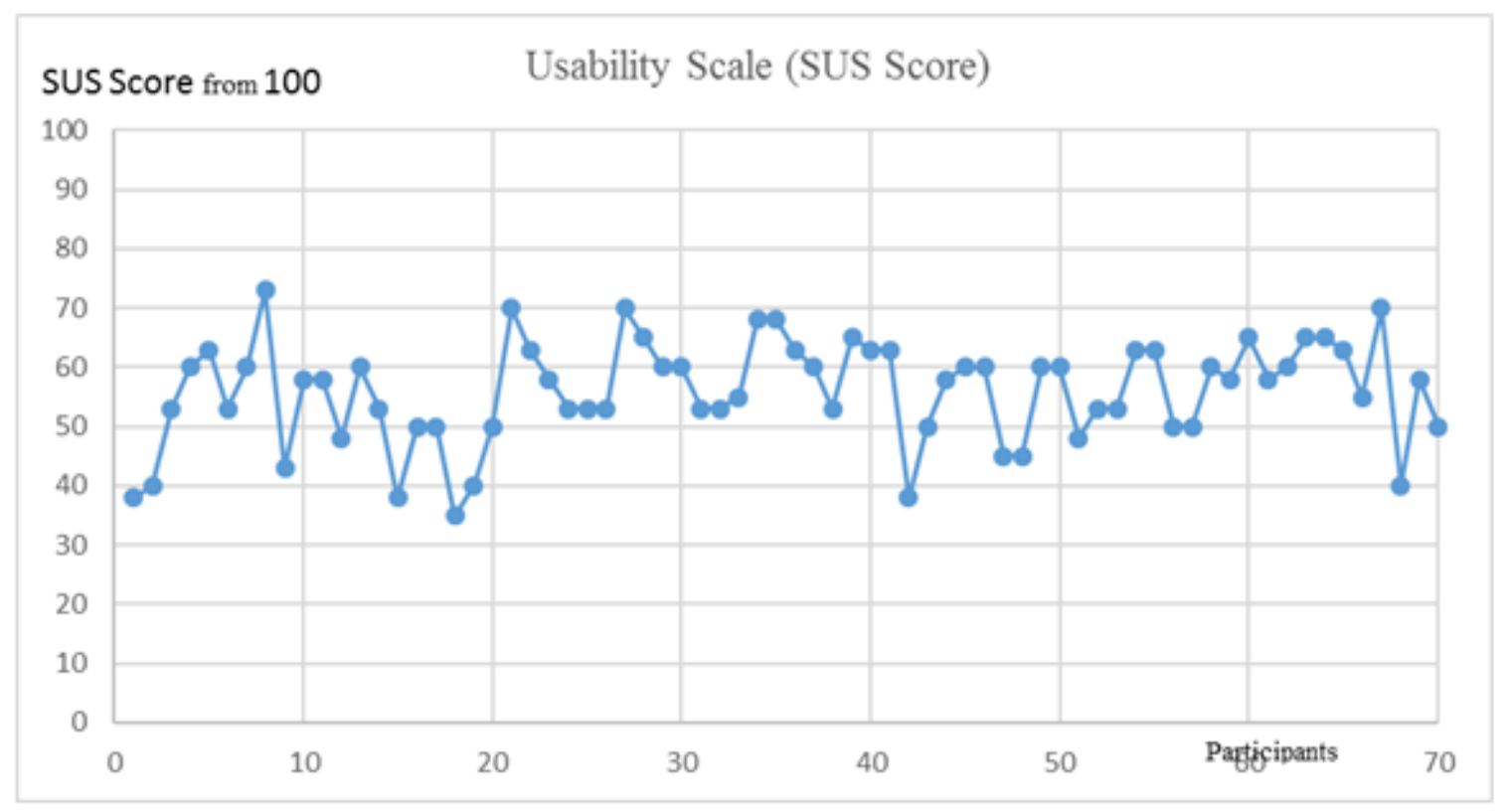

Figure 5. Questionnaire Results (SUS Score)

Intel creative interactive gesture camera is a perceptual computing camera designed to interact with computers in a more natural way through facial expression, gestures and voice. We used this camera in our experiment to capture the emotions of participants. The kit of this camera has different examples to capture emotions .(https://software.intel.com/en-us/articles/developingapplications-using-intel-perceptual-computing-technology,28/7/2017)

Intel camera change the way user interact with computer, making it more natural, intuitive, and immersive. Computers will be able to perceive our actions through hand gestures, finger articulation, speech recognition, face tracking, augmented reality, and more. To support 
International Journal of Managing Information Technology (IJMIT) Vol.10, No.2, May 2018 perceptual computing, Intel introduced the Intel® Perceptual Computing SDK, a library for pattern detection and recognition algorithms.https://software.intel.com/en-us/articles/developingapplications-using-intel-perceptual-computing-technology,28/7/2017)

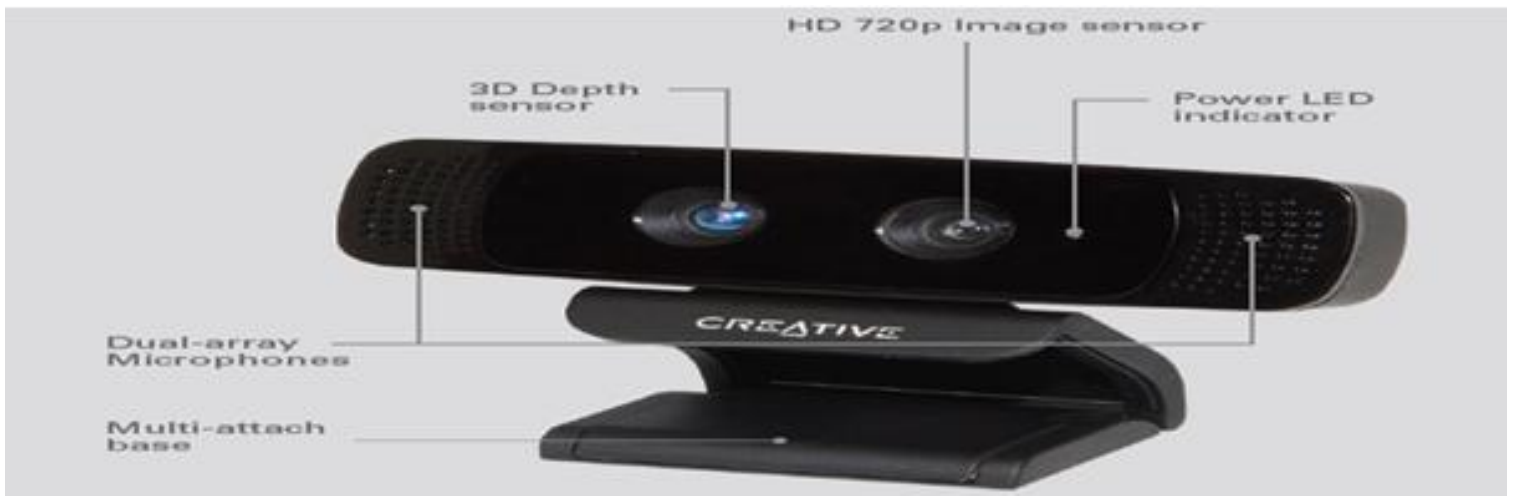

Figure 6. Intel Interactive Gestures Camera. (Reprinted from (Doss and Raj,2013))

We implement facial expressions example to capture emotions, the captured emotions (Anger, Contempt, Disgust, Fear, Joy, Sadness and Surprise), are saved in a text file. Then we take the emotions of each participant and place them in Microsoft Excel file. After that, we count the positive and negative emotions for each participant. I automatically analyzed the usability attitudes of participants depending on the extracted. The results are summarized in the following Figure:

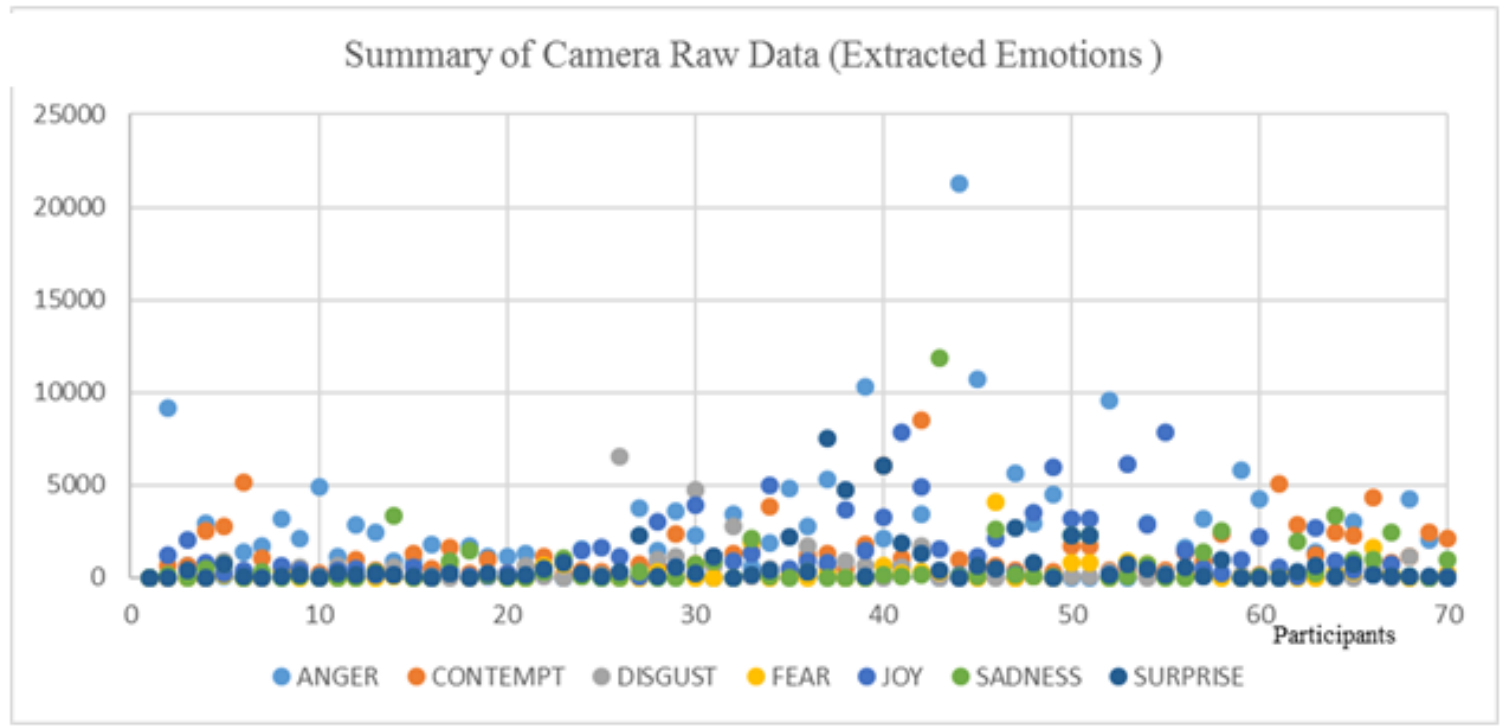

Figure7. Summary of Camera Emotions Data

The above figure contains seven emotions for each participant, and total numbers of these emotions.

After we collect the raw camera data, we should consolidate the data of camera and the data of questionnaire to be compared. The data must be have the same type (like be Likert scale(0-4)). This step is important to compare the data that we extract from camera (count of emotions) with questionnaire data (Likert scale). We will use the SPSS19 to change camera data to frequencies using $20^{\text {th }}$ percentiles (Gay, Airasian ,2003). Based on these frequencies we will create ranges that will represent the Likert scale responses as $(1=$ Strongly disagree, $2=$ Disagree, $3=$ Natural 
International Journal of Managing Information Technology (IJMIT) Vol.10, No.2, May 2018 ,4=Agree and 5Strongly agree) these for negative 6 emotions that we extract (Anger, Contempt, Disgust, Fear, Sadness and Surprise).But for positive emotion that we have (joy) we will do the opposite .

We will change the responses to become $(5=$ Strongly disagree, $4=$ Disagree, $3=$ Natural, $2=$ Agree and $1=$ Strongly agree). The final step is to calculate the usability score for camera data like questionnaire data. In previous section we calculate the SUS score or usability score multiply 4(04 Likert) by 10 (10 questions) to get score of questionnaire from 40 and to change it from 100 we should multiply by 2.5 . On other hand, For camera to we should multiply 7(emotions)by $4(0-4$ Likert) to get score from 28 and to change from 100 we should multiply by 3.57 .

The next figure shows camera data after converted to Likert scale:

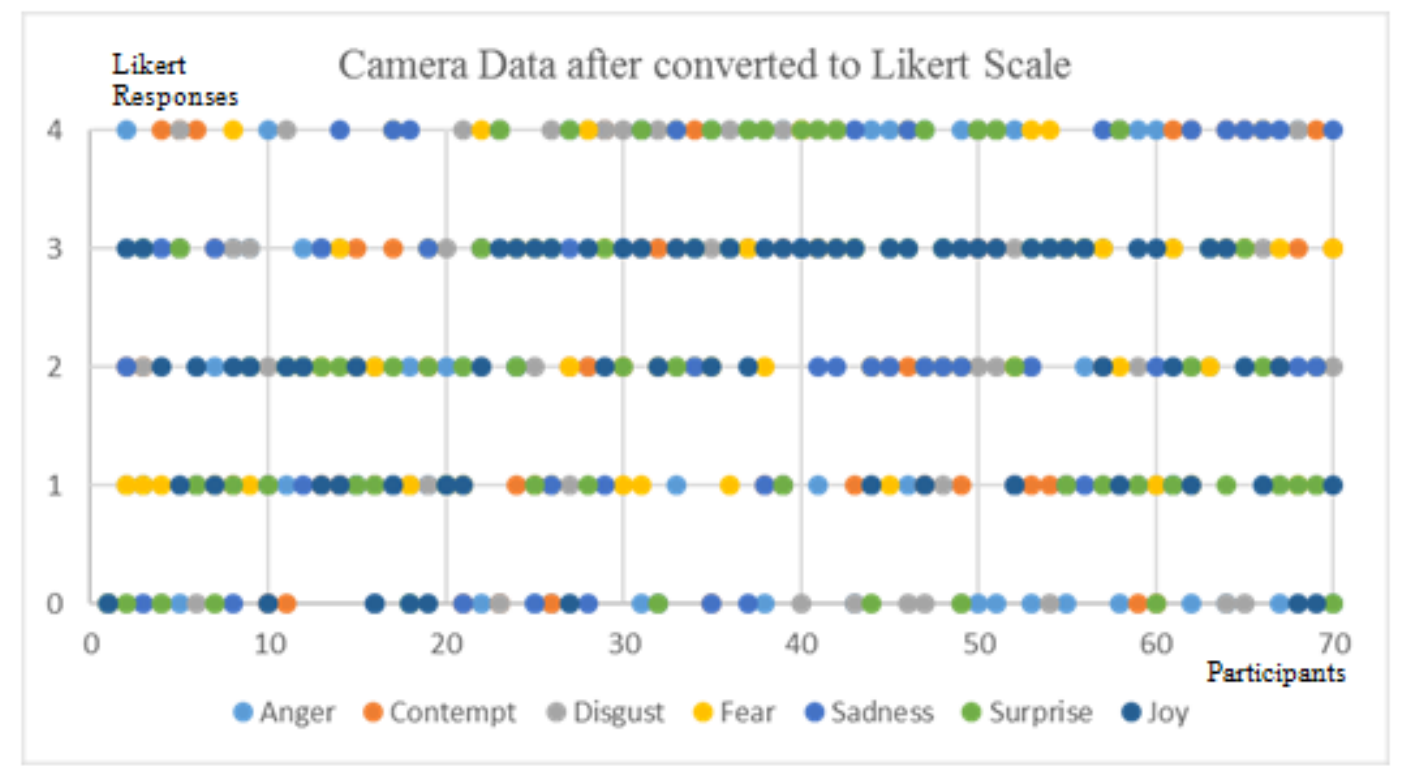

Figure 8. Camera Data after converted to Likert Scale

The next figure shows the usability score for camera data from 100:

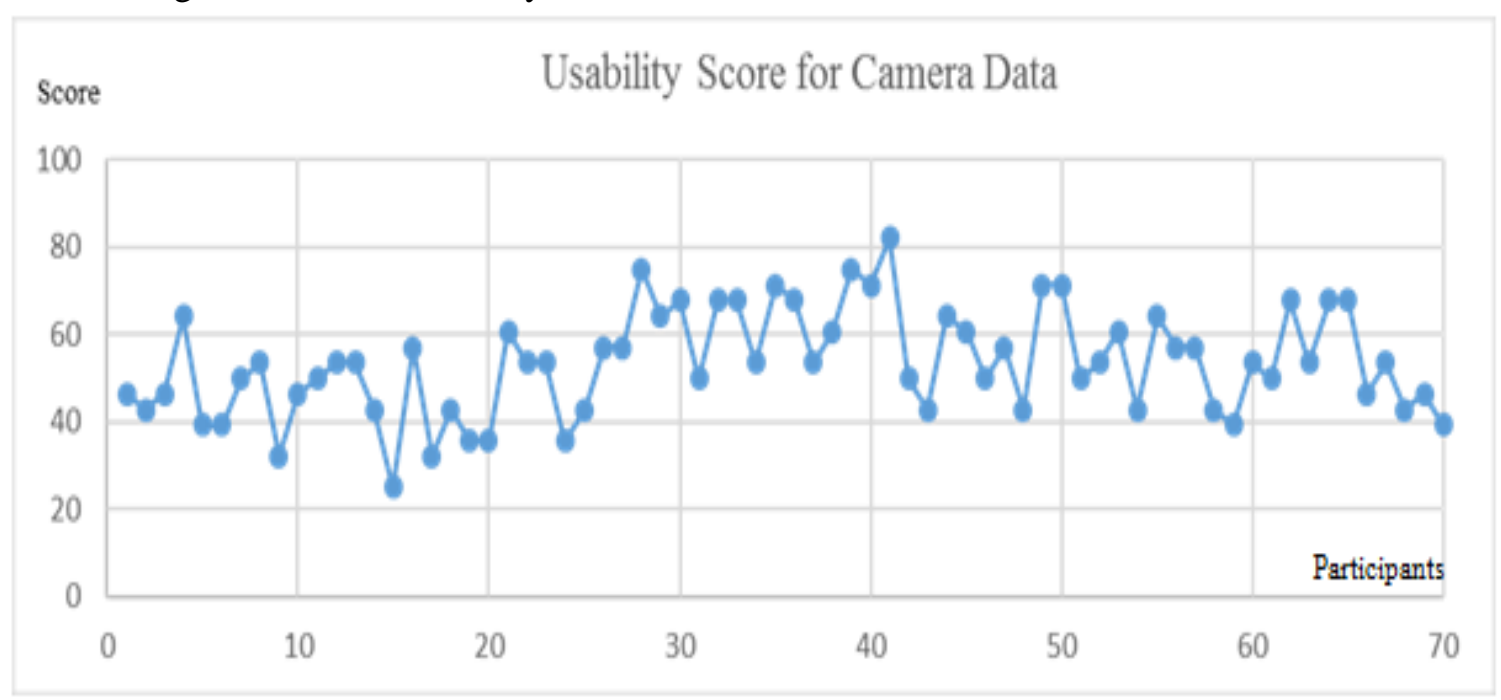

Figure 9. The usability score of camera data from 100 
International Journal of Managing Information Technology (IJMIT) Vol.10, No.2, May 2018

\section{DISCUSSION}

The main aim of experiment is to find a new valid tool to measure usability or user experience in automatic way that can be more sensitive and easier than SUS paper based questionnaire. To achieve our goal we use two valid tools; Intel interactive gesture camera and SUS (System Usability Score) questionnaire to measure the usability and user experience of Al-Quds University website.

We infer that, there is a total agreement between the usability results of the questionnaire and the usability results of the camera. To show the total agreement between the results, we will explore the quantitative and qualitative data for both camera data and questionnaire data. For quantitative data the next table is contain the basic statistical information about the SUS questionnaire usability score (from 100) and camera usability score (from 100), Participants(N)=70.

Table3. Basic statistical information for usability about SUS and camera

\begin{tabular}{|c|c|c|c|c|c|c|c|}
\hline Statistics & Mean & Median & $\begin{array}{c}\text { Standard } \\
\text { Deviation }\end{array}$ & Variance & Minimum & Maximum & Average \\
\hline $\begin{array}{c}\text { SUS } \\
\text { Questionnaire } \\
\text { Usability } \\
\text { Score }\end{array}$ & 55.68 & 57.50 & 8.732 & 76.254 & 35 & 73 & 55.9 \\
\hline $\begin{array}{c}\text { Camera } \\
\text { Usability } \\
\text { Score }\end{array}$ & 53.4990 & 53.5500 & 12.07197 & 145.733 & 24.99 & 82.11 & 53.5 \\
\hline
\end{tabular}

The above table shows that basic statistical information for both the SUS questionnaire usability score and camera usability score are very close and the camera can be a good alternative for SUS questionnaire.

The Cronbach alpha, which refers to reliability of measurements, is estimated as 0.498 for questionnaire data and 0.373 for camera data. These values indicate the strong of questionnaire and camera as instruments used in the evaluation (Harrati, Bouchrika, Tari, Ladjailia, 2016). The SUS questionnaire is valid measure tool for more than 25 years (Brooke, 2013). On the other hand, Intel interactive gestures camera and its application that we used is built on FAPs model .So, the two tools that we use are concurrent valid tools.

There are many ways to express SUS usability scores like acceptability ranges, adjective rating and grade scale .In 2009 Bangour, Kortum and Miller have study 3.500 SUS scores over one decade for different systems and technologies. They found a relation and correlation between SUS scores and people evaluate systems and products. People who evaluate systems and products use adjectives like good, excellent and poor. On other hand, they use scoring system ranging from 0 to 100 to interrupting SUS scores as percentage ,but it is not interrupt (Brooke,2013). The using of percentiles scores which give a more meaningful interrupting for SUS score (Sauro,2011)(Bangour, Kortumand Miller,2008). The next figure showing the original imagine of grade rankings of SUS scores from "Determining What Individual SUS Scores Mean: Adding an Adjective Rating Scale," by A. Bangor, P.T. Kortum, and J.T. Miller, 2009, Journal of Usability Studies. 
International Journal of Managing Information Technology (IJMIT) Vol.10, No.2, May 2018

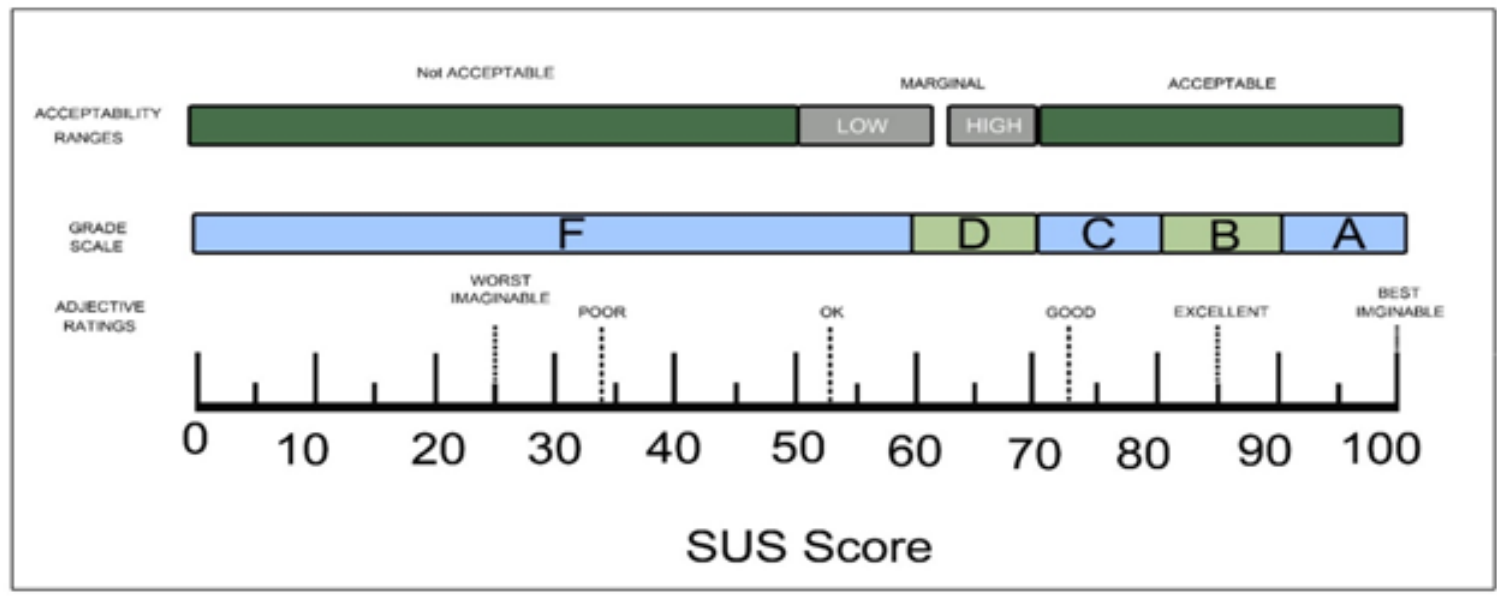

Figure 10. Grade Rankings of SUS Scores ( Bangor \& et al, 2009)

Implementing (Bangor, Kortum, and Miller) on our results of experiment (SUS and camera ) we can get the next figures :

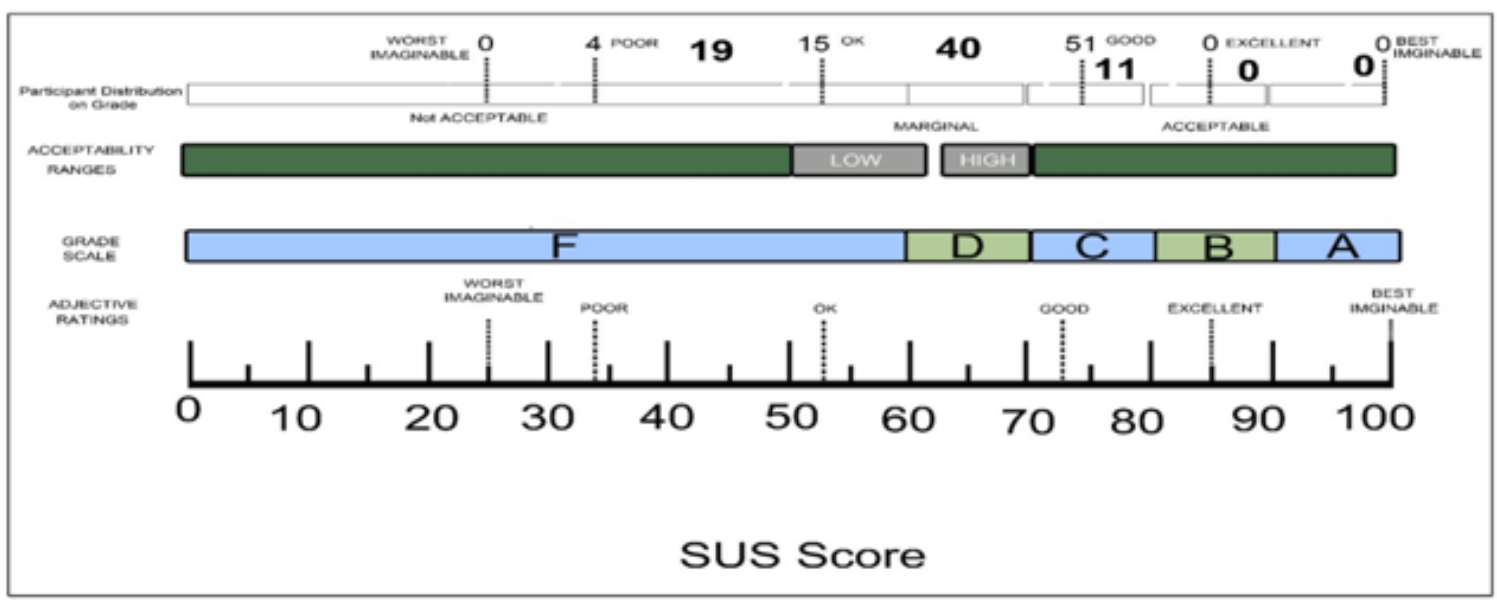

Figure 11. SUS Questionnaire Score results of our experiment

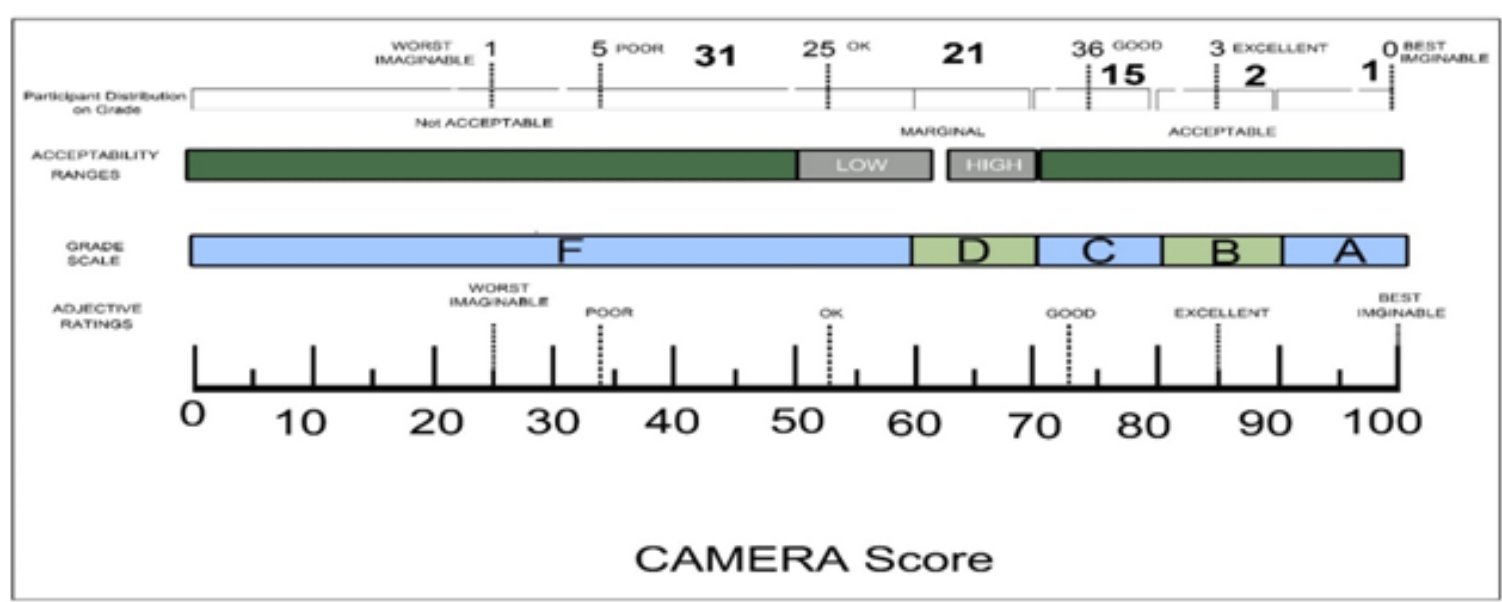

Figure (5-44): Camera Score results of our experiment 
International Journal of Managing Information Technology (IJMIT) Vol.10, No.2, May 2018

Implementing the Sauro and Lewis SUS Score grading (2015) (see table (5-14)) on usability score results of questionnaire and camera we will get the next figure:

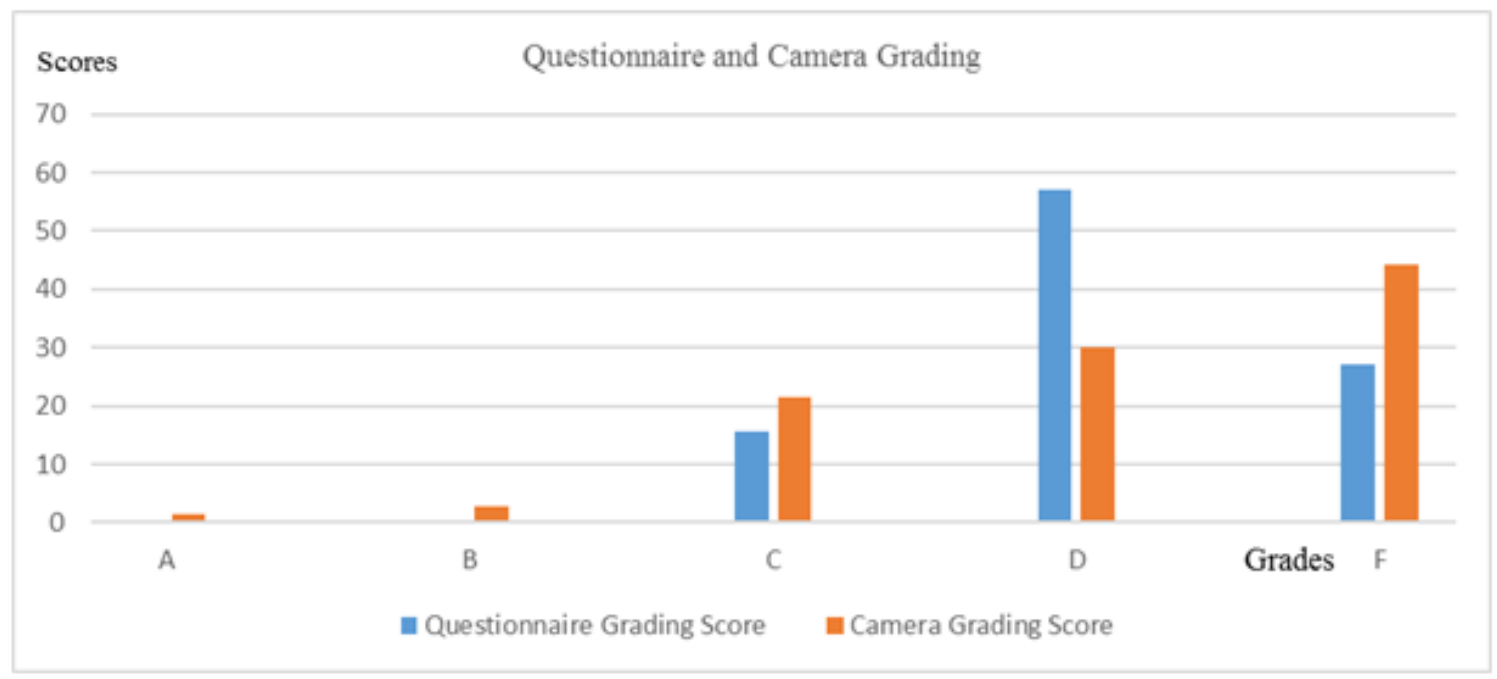

Figure 12 . The questionnaire and camera usability grading score

In figure11, we see how the scores grades are distributed for camera and questionnaire from 100. Beside, we notice that camera is more sensitive than questionnaire in capturing usability.

The qualitative data that we collected through the sessions with users are indicate that the users opinion is support the usability results of camera and questionnaire. As we mentioned the usability average score of SUS questionnaire is 55.9 and for camera is 53.5. These averages indicate that usability is below average (68) depending on (Sauro, 2011) (Bangour, Kortumand and Miller, 2008). In interviews, the participants have present key comments about the website of Al-Quds University. We asked the participants about the usability of website by mentioned the negative and positive points in site .One participant stated :( There are many negative points like moving between pages and update critical information on e-class) another participant stated :( I think the worst thing in website finding the desired link that I want to use and unclear icons that used in site to instruct the user). When we asked participant about the degree of ease and difficulty to access information from the website. He said (the degree of ease to access information is below median). In general, the participants have impression that website have some complicated in usability issues and should work to improve the site.

\section{CONCLUSIONS}

Human-computer interaction does not depend on traditional input devices, but it has exceeded the normal limits and has become very close to human-human interaction. In human-human interaction, the facial expressions and human gestures are the basic part of interaction beside the speech. Facial expressions and gestures have also become the basic part of human-computer interaction. Keyboard, mouse and other input devices have become old interaction tools, the new interactions tools are facial expressions and gestures like raising right eyebrow, raising left eyebrow, smiling etc. These new interaction tools are also indicators to evaluate usability or user experience of any computer application or program. This hidden relation between emotions and body language that include (facial expression and gestures ) gives the researchers the opportunity to investigate the affect state of human who uses computer device without explicitly communicating with it. Personally think that reading of nonverbal cues of user makes the evaluation operation of any application more efficient and more accurate while it decreases 
International Journal of Managing Information Technology (IJMIT) Vol.10, No.2, May 2018

annoyance to the user. The emotions or digitally transformed/converted emotions that result from the human-computer interactions have the same characteristics and aspects of emotions that results from human-human interactions, and we can use the same category approaches of emotions to implement them on digitally transformed/converted emotions. Therefore, methods for monitoring these digitally transformed/converted emotions can be developed and using these digitally transformed/converted emotions in measuring the usability of applications. Digitally transformed/converted emotions can be a good and a clear indicator to usability of any application.

We can infer digitally transformed/converted emotion by traditional ways from psychological behavior through blood pressure, eyelid, etc. but these traditional methods have problems make it not identical for use. The alternative methods that depend on reading the emotions by body language (facial expressions and gestures ) like Facial action coding system FACS that can be used in psychology and in computer science and the closet one to this model is MPEG or Facial Animation Parameter used only in computer science. Moreover, we can use hand over face gestures using the analysis method used by Mahmoud and Robinson.

This research evolve new model (MUDE) depending on the methods (FACS, FAP and Pease \& Pease) that inferring digitally transformed /converted emotions that results fronm human computer interaction. MUDE Model can be used to measure the User Experience of user using the expected emotions that user expressed before, during and after interaction with application or software. This new model makes the way of measuring so natural and not bothering users during the evaluation and measuring process. In addition, it provides us with the needed information without asking users. Furthermore, it is more accurate and truthful way, by which the researcher can determine the usability of application and user experience of user.

The method can be used to measure the impression of any human not only in HCI domain, but also in diverse domains like coffee shops, to take impression of customers about new drinks. We can also use the model in airports to take feedback from passengers about services that have been served to them. I think that this model will have a wide range of uses in different domains. Beside the model this thesis introduce a new experiment that implement the MUDE model and find a new valid tool to measure usability or user experience in automatic way that can be more sensitive and easier than SUS paper based questionnaire. To achieve our goal we use two valid tools; Intel interactive gesture camera and SUS (System Usability Score) questionnaire to measure the usability and user experience of Al-Quds University website. The qualitative data in experiment that we collected through the sessions with users are indicate that the users opinion is support the usability results of camera and questionnaire. As we mentioned the usability average score of SUS questionnaire is 55.9 and for camera is 53.5. These averages indicate that usability is below average (68) depending on (Sauro, 2011) (Bangour, Kortumand and Miller, 2008).So, the results give us indicator that camera can be valid tool to user experience and usability and there is a new way to develop new accurate and reliable methods.

This field of new interactions have its principles and rules that should be studied to successfully extract the accurate indications and meaning of the facial expressions and human gestures, in order to develop applications and programs that are capable of understanding these cues.

To fully understand this subject, we must have a sufficient knowledge of models like Ekman and FAPs. We need to develop new models to enhance the overall operation cycle; also, we have experimental proofs that these new interactions tools are real sources of usability and user experience data. 
International Journal of Managing Information Technology (IJMIT) Vol.10, No.2, May 2018

\section{FUTURE WORK AND LIMITATIONS}

We concluded that the human-computer interactions tools have advanced to become very close to human-human interactions. We should work on new models to contribute in the development of human-computer interactions. On the other hand, we should work hard to develop new applications and programmers that are compatible with these interactions. We need to concentrate on applications utilizing from emotions extracted from facial expressions and gestures to evaluate usability and user experience without bothering the users. However, there are many limitations and constraints like hardware slow improvement in the domain of monitoring facial expressions and gestures. A limited number of companies manufacture the monitoring hardware tools. Another limitation is that sometimes the facial expressions of users do not indicate the real psychological state of human, in some situations the facial expressions shows sadness expression, while in reality the human may not be in this situation. The third limitation is that facial movements is only one of other nonverbal cues, but we need to consider the all-nonverbal cues that occur to understand the real psychological state. The next limitation is that people faces are different, some have expressing faces, others do not have clear expressing faces that are difficult to read, and hence hardware tools like camera will not be completely accurate. The finial limit is that reading facial expressions and gestures is not acceptable for people in some societies, and may be considered a controversial topic in some cultures. On the other hand, there are many open roads to future work there main way to work on hardware of Intel interactive gestures camera to develop it to be more accurate, specific and sensitive.

There is main way to develop its applications like developing new application that give us the usability and user experience of any application directly comparing with SUS questionnaire. The third main way is working on MUDE model, which needs developing, and more become widely to cover more areas like evaluate the satisfaction of customers about any service in cafe or restaurant.

\section{PROblems}

1- The research topic is very difficult and have limited number in references.

2- The camera that I used (Intel interactive gesture camera) take long period to be imported (about 6 months).

3- Many people refused to participate in the experiment (especially girls).

4- No budget for scientific research in Al-Quds University.

5- This research needs full time researcher to accomplish the research.

\section{REFERENCE}

[1] Andreassi , J.(2000): Human behavior and Physiological response,Forth Edition. Lawrence Erlbaum Association Inc. Publishers, USA.

[2] Bangor, A.\&et al. (2009): Determining What Individual SUS Scores Mean: Adding an Adjective Rating Scale. Journal of Usability Studies, 4, pp. 114-123.

[3] Shneiderman, B.\& et al. (2002): Social and Psychological Influences on Computer User Frustration. (Technical Research Report, HCIL-2002-19) .University of Maryland Human - Computer-Interaction Lab. Maryland. 
International Journal of Managing Information Technology (IJMIT) Vol.10, No.2, May 2018

[4] Bettadapura, V. (2012): Face Expression Recognition and Analysis: The State of the Art College of Computing, Georgia Institute of Technology. Cornell University Library.

[5] Branco , P. (2006):Computer-based Facial Expression Analysis for Assessing User Experience.University of Minho. Portugal.

[6] Brave, S., Nass, C. (2003): Emotion in Human-Computer Interaction. In: A.Sears, J.Jacko (Eds.) Human -Computer Interaction Fundamentals (pp.53-67) .Taylor and Frances Group, USA.

[7] Brooke,J.(2013). SUS: A Retrospective. Journal of Usability Studies, 8, pp. 29-40.

[8] Brooke,J.(1990). SUS - A quick and dirty usability scale. US. (http://www.usability.gov/how-to-andtools/methods/system-usability-scale.html, 19/1/2016)

[9] Biyaye, M. (2009). Non-verbal Emotional Dictionary Automatic generation of facial expressions from text input. Delft University of Technology. Holland.

[10] Damasio, A. (1994): Descartes' Error: Emotion, Reason, and the Human Brain, First Edition. Putnam Publishing Group, New York.

[11] Darwin, C. (1872):The expression of the emotions in man and animals, London, UK.(http://darwinonline.org.uk/content/frameset?pageseq=1\&itemID=F1142\&viewtype=text,20/4/2015)

[12] Dumas ,J., Redish ,J.(1999): A Practical guide to usability testing,( Revised Edition). Intellect Books, England.

[13] Doss, S., Raj, C.(2013): Intel Interactive gestures camera ,USA. (https://software.intel.com/enus/articles/developing-applications-using-intel-perceptual-computing-technology,19/6/2015)

[14] Ekman, P., Friesen, W. (1971): Constants across cultures in the face and emotion. Journal of postnatally and psychology,17,pp 124-129.

[15] Ekman, P., Friesen, W. (1975): Unmasking the Face. A guide to Recognizing Emotions From Facial Clues, First Edition. Prentice-Hall, USA.

[16] Ekman, P. (1982): Emotion in the Human Face, Second Edition. Cambridge University Press, USA.

[17] Ekman, P. (2003): Emotions Revealed: Recognizing Faces and Feelings to Improve Communication and Emotional Life, First Edition. Times Book, USA.

[18] Ekman, P., \& et al. (2010): The manual of FACS .(https://www.slideshare.net/wooo17/manual-1st)

[19] Fasel, B. \& Luttin, J. (2002): Automatic facial expression analysis: a survey. Pattern Recognition. Elsevier Science.

[20] Findlater,\& L.et al . (2009): Ephemeral adaptation: The user of gradual onset to improve menu selection performance. Proceedings of ACM CHI '09,4-9 April 2009.USA. pp. 1655-1664.

[21] Faulkner, L. (2006): History of Usability Profession .usabilitybok.org. (http://www.usabilitybok.org/what-is-usability/history-of-usability, 30/5/2015).

[22] Grandjean , D.\& et al. (2008):Conscious emotional experience emerges as a function of multilevel, appraisal-driven response synchronization. Elsevier Science. Consciousness and Cognition, 17, pp.484-495.

[23] Guo, F.(2012): More Than Usability: The Four Elements of User Experience. uxmatters.com. USA. (http://www.uxmatters.com/mt/archives/2012/04/more-than-usability-the-four-elements-of-userexperience-part-i.php, 19/6/2015) 
International Journal of Managing Information Technology (IJMIT) Vol.10, No.2, May 2018

[24] Harrati, N. \& et al. (2016):Exploring User Satisfaction for E-learning Systems via Usage -Based Metrics and System Usability Scale Analysis. Elsevier Science. Computers in Human Behavior, 61, pp. 463-471.

[25] Hartson, H. \& et al (1996) :Remote evaluation: The Network as an Extension of the Usability Laboratory. In Proceedings of the Conference on Human Factors in Computing Systems(CHI'96), 13-18 April 1996, ACM, Canada. pp. 228-235.

[26] Hartson, R., Pyla, P. (2012) :The UX Book: Process and Guidelines for Ensuring A Quality User Experience.Morgan Kaufmann Publisher, USA.

[27] Harty, J. (2011): Finding usability bugs with automated tests. Communications of the ACM, 54, pp. 44-49.

[28] Hassenzahl, M. (2013): User Experience and Experience Design. In: M. Soegaard, R.Dam (Eds.). The Encyclopedia of Human-Computer Interaction (Chapter 3).The Interaction Design Foundation, Aarhus, Denmark.

[29] Highfield, R. \& et al .(2009): How your looks betray your personality. New Scientist- Magazine issue 2695.UK(https://www.newscientist.com/article/mg20126957-300-how-your-looks-betray-yourpersonality/,17/5/2015)

[30] ISO 92411pt 11 (1998): ISO 92411pt 11-standard. Iso.org. Geneva, Switzerland. (http://www.iso.org/iso/catalogue_detail.htm?csnumber=16883, 22/5/2015)

[31] ISO 9241-210 (2010): ISO 9241-210-standard Iso.org. Geneva, Switzerland. (https://www.iso.org/obp/ui/\#iso:std:iso:9241:-210:ed- 1:v1: en,12/6/2015)

[32] Kabac, M.\& et al .(2015):An evaluation of the DiaSuite Toolset by Professional Developers . Proceedings of the 6th Workshop on Evaluation and Usability of Programming Languages and Tools (PLATEAU), October2015. ACM, USA .pp. 9-16.

[33] Kleinginna, P., Kleinginna, A. (1981): A categorized list of emotion definitions, with suggestions for a consensual definition. In: Motivation and Emotion, (pp. 345-379).Springer. USA.

[34] Krug, S. (2006): Don't Make Me Think. A common sense approach to web usability,Secound Edition. New Riders Publishing Berkeley, USA.

[35] Lewis, H.(2012): Body Language :A guide for Professional ,(Third Revised Edition). SAGE Publications, India.

[36] Lewis J., Sauro, J. (2009): The Factor Structure of the System Usability Scale .In: M. Kurosu (Ed.), Human Centered Design, HCII 2009, 2009.Springer, Verlag, Berlin, Heidelberg. Pp. 94-103.

[37] Lewis ,J. \& et al . (2015) : Investigating the Correspondence Between UMUX -LITE and SUS Scores Design .In: User Experience and Usability: Design Discourse (DUXU2015),2015.Springer,USA. pp 204-211

[38] Lewis ,J . \& et al .(2013) :UMUX-LITE -When There's No Time for the SUS .In: Proceeding CHI '13 Proceedings of the SIGCHI Conference on Human Factors in Computing Systems, 27 April-2 May 2013.ACM,France.pp. 2099-2102.

[39] Mahmoud, M., Robinson, P. (2011): Interpreting Hand-Over-Face Gestures. University of Cambridge, UK

[40] Maslow, A. (2012): Toward Psychology of Being, Third Edition. John Wiley and Sons, Canada. 
International Journal of Managing Information Technology (IJMIT) Vol.10, No.2, May 2018

[41] Mifsud, J. (2011): The Difference (and Relationship) Between Usability and User Experience.(http://usabilitygeek.com/the-difference-between-usability-and-user-experience, $19 / 6 / 2015)$

[42] Moffatt, K. \& et al. (2008): Hover or tap? Supporting pen-based menu navigation for older adults. In: Proceedings of the 10th international ACM SIGACCESS conference on Computers and accessibility, 13-15 October2008.ACM, Canada pp.51-58.

[43] Moville, P.(2004): User Experience Design.semanticstudios.com. Michigan .USA.(http://semanticstudios.com/user_experience_design/, 19/6/2015)

[44] Nielsen, J. (1993): Usability engineering, First Edition.. Morgan Kaufmann Publisher. USA.

[45] Orfanou, K .\& et al. (2015): Perceived Usability Evaluation of Learning Management Systems: Empirical Evaluation of the System Usability Scale. The International Review of Research in Open and Distributed Learning (IRRODL). Athabasca University .Greece. (http://www.irrodl.org/index.php/irrodl/article/view/1955/3262, 19/6/2016)

[46] Pease, A., Pease, B. (2004): The Definitive Book of Body Language How To Read Others' Thoughts By Their Gestures, First Edition .Pease International, Australia.

[47] Ruoti, S. , Seamons, K.(2016) : Standard Metrics and Scenarios for Usable Authentication . In: Symposium on Usable Privacy and Security (SOUPS) 2016, 22-24 June 2016, Colorado. (https://www.usenix.org/system/files/conference/soups2016/way_2016_paper_ruoti_metrics.pdf,19/7/ 2016)

[48] Russell ,J., Fernandez-Dols ,J. (1997): The Psychology of Facial Expression,First Edition. Cambridge University Press, UK.

[49] Sauro,J.(2011): Measuring Usability with the System Usability Scale (SUS). Measuringu.com. Denver, Colorado, USA ( http://www.measuringu.com/sus.php, 19/1/2016)

[50] Sauro,J.(2013) : A Brief History of Usability. Measuringu.com. Denver, Colorado, USA (https://measuringu.com/usability-history/, 30/5/2015).

[51] Shneiderman, B. (2002): .Leonardo's laptop: human needs and the new computing technologies, First Edition. MIT Press,USA.

[52] Shah, K.\& et al. (2014):.A survey on Human Computer Interaction Mechanism Using Finger Tracking .In: International Journal of Computer Trends and Technology (IJCTT). (https://pdfs.semanticscholar.org/6fb2/5d71f9d7d56d1c89a92ce5eab0b46f41e164.pdf, 16/5/2105)

[53] Soegaard, M.(2012): The History Of Usability: From Simplicity To Complexity. Smashing Magazine, Germany. (http://www.smashingmagazine.com/2012/05/the-history- of-usability-from-simplicity-tocomplexity/, 18/7/2015)

[54] Tullis, T., Albert, B. (2008): Measuring the User Experience: Collecting, Analyzing, and Presenting Usability Metrics, First Edition. Morgan Kaufmann Publisher, USA.

[55] The Moving Pictures Experts Groups (MPEG) Website (2015): mpeg.chiariglione.org (http://mpeg.chiariglione.org/, 30/15/2015)

[56] Usability (2016):Usability.org (http://www.usability.org/, 19/1/2016)

[57] UXPA (2014): User Experience Professionals Association. uxpa.org. USA.(http://uxpa.org/resources/definitions-user-experience-and-usability, 12/6/2015) 
International Journal of Managing Information Technology (IJMIT) Vol.10, No.2, May 2018

[58] Valstar, M. (2008): Timing is everything a spatio-temporal approach to the analysis of facial Actions. Imperial College of Science, Technology and Medicine.University of London, UK.

[59] Wikiversity (2015): wikiversity.org

(https://en.wikiversity.org/wiki/Motivation_and_emotion/Book/2014/Plutchik\%27s_wheel_of_emotio ns, $22 / 5 / 2015)$

[60] Wikipedia Usability (2015): Usability. (https://en.wikipedia.org/wiki/Usability, 19/6/2015)

[61] Wikipedia Emotions (2015): Emotion (https://en.wikipedia.org/wiki/Emotion\#Ancient_Greece_and_Middle_Ages, 22/5/2015)

[62] Wikipedia Appraisal(2015): Appraisal Theory (https://en.wikipedia.org/wiki/Appraisal_theory, 22 /5 / 2015)

[63] Wikipedia FACS (2015): Facial Action Coding System.(https://en.wikipedia.org/wiki/Facial_Action_Coding_System, 12/5/2015)

[64] Zhao, Y. (2012): Human Emotion Recognition from Body Language of the Head using Soft Computing Techniques. Ottawa-Carleton Institute for Computer Science (OCICS)Faculty of engineering .University of Ottawa, Canada. 